\title{
New isotopic evidence for changes of the erosion and weathering on the northeast South American margin
}

\author{
PAULINE CORENTIN ${ }^{1}$, EMMANUELLE PUCÉAT ${ }^{2}$, \\ PIERRE PELLENARD ${ }^{2}$, MICHEL GUIRAUD ${ }^{2}$, GERMAIN \\ BAYON $^{3}$, THIERRY ADATTE ${ }^{4}$ AND JUSTINE BLONDET ${ }^{5}$ \\ ${ }^{1}$ Université Bourgogne Franche-Comté, UMR CNRS 6282 \\ ${ }^{2}$ Université Bourgogne Franche-Comté \\ ${ }^{3}$ IFREMER \\ ${ }^{4}$ Lausanne University \\ ${ }^{5}$ Laboratoire Biogéosciences, UMR CNRS 6282/uB, Université \\ Bourgogne Franche-Comté \\ Presenting Author: pauline.corentin@u-bourgogne.fr
}

The global climate cooling recorded during the late Cretaceous marks the initiation of the last greenhouse-icehouse transition. The concomitant decrease in atmospheric $\mathrm{CO}_{2}$ levels suggests an implication of processes governing the carbon cycle. If a decrease in $\mathrm{CO}_{2}$ release by volcanism can explain part of the cooling, the role of continental silicate weathering that drawdown $\mathrm{CO}_{2}$ still remains overlooked so far.

The aim of this study, intended as a first step to explore the potential impact of this process on the late Cretaceous cooling, is to determine the evolution of chemical weathering of the northeastern South American margin during the major tectonic uplift that affected part of the South American continent at that time. A new proxy of silicate weathering intensity $\left(\Delta \varepsilon_{\mathrm{Hf}}\right)$, based on the coupled Lu-Hf and $\mathrm{Sm}-\mathrm{Nd}$ isotope systems in clays (Bayon et al., 2016), is applied here on sediments from ODP site 1259 (Demerara Rise). Mineralogical proxies are used to assess the physical erosion.

The evolution of clay mineral assemblages determined in this work show a large dominance of smectite that points to a relatively hydrolyzing climate with contrasted seasons. A slight increase in primary clay minerals associated to an increase in Kfeldspar and plagioclase abundances could indicate an erosive pulse during the Santonian-Campanian. A concomitant increase in clay $\varepsilon_{\mathrm{Nd}(\mathrm{t})}$ values likely reflects a change in the source of the eroded material, possibly induced by a modification of the drainage areas during the tectonic pulse.

Importantly, the $\Delta \varepsilon_{\mathrm{Hf}}$ evolution doesn't show a clear correspondence with the tectonic pulse identified from mineralogy. By contrast, $\Delta \varepsilon_{\mathrm{Hf}}$ evolution appears to follow the global climatic signal. $\Delta \varepsilon_{\mathrm{Hf}}$ points to a decrease in chemical weathering of the margin from the Coniacian to the Middle Campanian, during the global cooling depicted by benthic foraminifera $\delta^{18} \mathrm{O}$, followed by an increase in chemical weathering until the end of the Campanian, during a phase of relative warming. The tectonic pulse may have been too limited in the northeast South America to impact chemical weathering rates that could rather have been driven in this area by variations in local temperatures.

Bayon et al. (2016) EPSL 438, 25-36. 